\title{
O pensamento de Roberto Simonsen e suas sintonias internacionais
}

\author{
Título: Entre a história e a economia. O pensamento econômico de Roberto Simonsen \\ Autor: Luiz Felipe Bruzzi Curi \\ Edición: Alameda, São Paulo, 2015. 330pp.
}

ISBN. 9788579393372

\author{
Alexandre MACCHIONE SAES \\ Universidade de São Paulo
}

Roberto Cochrane Simonsen (1889-1948), engenheiro de formação, foi empresário, líder industrial e, por conta de suas contribuições no campo da história econômica, um relevante intérprete do Brasil. Nascido no Rio de Janeiro, Simonsen ascendeu no cenário político nacional por meio de sua atuação como industrial no estado de São Paulo. Entre as décadas de 1920 e 1940, percorreu uma trajetória profissional como empresário no ramo da construção e como professor de história econômica na Escola Livre de Sociologia e Política de São Paulo; foi também presidente da Federação das Indústrias do Estado de São Paulo e do Centro Industrial do Brasil, assim como deputado classista, representante das entidades empresarias tanto na Constituinte de 193334 como na legislatura iniciada em 1935; foi, por fim, quadro do governo de Getúlio Vargas, durante o Estado Novo (1937-1945), integrando o Conselho Federal de Comércio Exterior e o Conselho Nacional de Política Industrial e Comercial. Se Simonsen foi figura atuante na vida pública brasileira, como defensor da indústria por meio do protecionismo e do planejamento, sua influência intelectual como formulador de uma intepretação sobre a história do Brasil, todavia, não foi menos expressiva.

Nesse sentido, o livro de Luiz Felipe Bruzzi Curi, Entre a história e a economia: o pensamento econômico de Roberto Simonsen, resultado de sua pesquisa no Programa de PósGraduação em História Econômica da Universidade de São Paulo, repisa a trajetória de uma das mais importantes lideranças empresariais brasileiras da primeira metade do século XX. Não se trata de um estudo pioneiro sobre o autor, afinal a relevância de Roberto Simonsen para a história brasileira estimulou a publicação de outros trabalhos sobre a vida do industrial. No entanto, as contribuições existentes sobre Simonsen seguiam, até então, ou na direção de observar seus escritos por meio de sua trajetória profissional, isto é, como um representante dos industriais de uma "burguesia industrial" -, ou de apontá-lo como um pioneiro do desenvolvimentismo no Brasil, isto é, da corrente teórica que se estabeleceria no campo de batalha da política econômica brasileira somente a partir dos anos 1950, depois do falecimento do autor, em 1948.

A obra de Luiz Felipe Bruzzi Curi apresenta, por sua vez, duas originais contribuições para a análise da trajetória de Roberto Simonsen e, em especial, de seu pensamento econômico. A primeira contribuição da obra se vale da perspectiva da difusão internacional das ideias econômicas para avaliar detalhadamente o espaço teórico em que se verifica a construção da interpretação de Roberto Simonsen sobre a economia brasileira. Por meio dessa metodologia, Bruzzi conseguiu, de maneira bastante consistente, superar parte da literatura sobre Roberto Simonsen. Ao acreditar que o Brasil não dispunha de um espaço de debate e de construção de ideias econômicas antes do pós-Segunda Guerra Mundial, esta historiografia tendeu a ver em Simonsen apenas um antecipador de elementos do desenvolvimentismo. Reconstruindo as influências e sintonias de Simonsen, não obstante, Bruzzi apresenta um ambiente amplo e rico de ideias econômicas em que o autor estava inserido. Supera, assim, a ideia de que haveria um "vazio teórico" nas disputas brasileiras de política econômica, anteriores aos anos 1950, como se verifica na obra de Ricardo Bielschowsky, Pensamento Econômico Brasileiro: o ciclo ideológico do desenvolvimentismo (1930-1964). Ademais, supera o risco do anacronismo, ao não imputar aos trabalhos de Simonsen perspectivas que estariam presentes no debate econômico somente anos mais tarde.

Assim, por meio da literatura resgatada por Simonsen em suas obras, Bruzzi demonstra como o industrial buscou em autores russos como S. N. Prokopovich e Waldimir Woytinsky, ou em 
alemães como Karl Rodbertus e Adolph Wagner, argumentos para sustentar a defesa de políticas protecionistas ou de maior intervenção do Estado na economia. Não significava um alinhamento definitivo com esses autores ou uma literal reprodução das teorias estrangeiras em seus textos, relatórios e discursos; mas tratava-se de uma assimilação de conceitos, dados e ideias arregimentados para legitimar seus interesses e para reforçar seus argumentos. Sua preocupação em buscar no exterior literatura que pudesse informar e aprimorar seus argumentados para a promoção do desenvolvimento industrial do país fica evidente com a assimilação da obra do romeno Mihail Manoilescu: Simonsen teria, inclusive, patrocinado a tradução de Teoria do protecionismo e permuta internacional em 1931, por meio do Centro das Indústrias do Estado de São Paulo. Vale o mesmo argumento para o encontro de Simonsen com o livro A teoria do planejamento econômico e social de Carl Landauer, logo após sua publicação em 1944, para embasar seu relatório que sustentava a necessidade do planejamento para a economia brasileira durante a chamada "controvérsia do planejamento", em que teria como seu oponente o economista liberal Eugênio Gudin.

A segunda contribuição da obra Entre a história e a economia para a análise do pensamento econômico de Roberto Simonsen é a ênfase dada por Bruzzi Curi ao papel desempenhado pela história na interpretação econômica do industrial. Nesse sentido a aproximação de Simonsen com os chamados intérpretes do Brasil deve ser reforçada: assim como seus contemporâneos, Gilberto Freyre, Sérgio Buarque de Holanda e Caio Prado Jr., Roberto Simonsen precisou mergulhar no passado do país para desvendar os limites de uma economia colonial. No livro História Econômica do Brasil, de 1937, apresentou uma economia cuja dinâmica cíclica, ao impor processos de produção e dilapidação da riqueza, não permitia a transmissão de legados duradouros para a construção da nação. A história era, portanto, instrumento poderoso para refutar a ideia de uma divisão internacional do trabalho, questionando teses de uma vocação agrária do Brasil, e para defender a industrialização como caminho de superação desse passado colonial mediante políticas deliberadas.

Entre a história e a economia deve ser recebido como um trabalho que, com grande sensibilidade, conseguiu retirar o empresário-intelectual Roberto Simonsen de uma perspectiva estritamente classista, que enfatizava apenas seu papel de representante da burguesia industrial. $\mathrm{O}$ livro também redimensiona o legado teórico de Simonsen sem incorrer numa análise de sua estrutura teórica por meio das lentes anacrônicas dos debates desenvolvimentistas que ocorreriam somente nos anos do pós-guerra. Conforme Luiz Felipe Bruzzi Curi, Simonsen construiu seu pensamento econômico não somente em profunda sintonia com a literatura internacional, do século XIX ao período entre guerras, como também fincou sólidos alicerces na análise histórica para conseguir compreender os reais desafios de uma economia periférica. Para Roberto Simonsen, portanto, a defesa da indústria no Brasil não teria apenas um sentido coorporativo, mas seria parte de uma interpretação orientada para a superação do passado colonial brasileiro. 